\title{
Tripanosomiasis canina: una zoonosis presente en la comunidad de Getsemaní
}

\author{
Marta Bonilla ${ }^{1} \bowtie$, Marco V. Herrero Acosta ${ }^{1}$, Andrea Urbina Villalobos ${ }^{2}$, Gaby Dolz $^{1}$ \\ 1 Laboratorio de Docencia e Investigación en Medicina Poblacional, Programa MEDPOB, Escuela de Medicina \\ Veterinaria, Universidad Nacional, Costa Rica. Email: mabongo27@gmail.com, herrero1958@hotmail.com, \\ gaby.dolz.wiedner@una.cr \\ 2 Laboratorio de Zoonosis, Escuela de Medicina Veterinaria, Universidad Nacional, Costa Rica. Email: \\ andreaurbina3@gmail.com
}

La Enfermedad de Chagas es una enfermedad zoonótica causada por el protozoario flagelado Trypanosoma cruzi, que puede infectar a humanos, animales domésticos y silvestres. El principal vector de la enfermedad en Costa Rica es el insecto hematófago Triatoma dimidiata. En la comunidad de Getsemaní, en Heredia, se ha reportado previamente la presencia de vectores y casos en humanos y caninos. En un estudio transversal, realizado en 177 viviendas de Getsemaní, se estableció en 21 (11.9 $\%)$ viviendas la presencia del vector y $14(66 \%)$ de estas viviendas ya contaban con nidos del vector. Del total de los vectores recolectados, el $55 \%$ (42/77) se encontraban infectados con T. cruzi, mientras que, de los 289 caninos analizados, 30 (10.4 \%) se encontraron infectados con el protozoario. El objetivo de esta investigación fue determinar si el ciclo de transmisión de la tripanosomiasis canina se encuentra activo en la comunidad de Getsemaní.

Se realizó un análisis longitudinal durante 16 meses con 55 caninos negativos para T. cruzi: 25 perros que vivían en casas en donde se había determinado previamente la presencia del vector y 30 perros que vivían en casas sin presencia del mismo. Los perros se analizaron 4 veces en intervalos de 4 meses. Durante el periodo de investigación, se encontraron 6 (10.9 \%) casos de nuevas infecciones en caninos. Todos los casos nuevos se detectaron en hogares con antecedentes de presencia del insecto. Se concluye, que las infecciones de T. cruzi en caninos se mantienen activas en la comunidad de Getsemaní, probablemente asociadas a su presencia en la vivienda y alrededores. Debido a que el ciclo de transmisión de tripanosomiasis se encuentra activo en Getsemaní, se recomienda alertar a la comunidad y entidades de salud, para que tomen medidas en la eliminación del vector. 